\title{
Plano de aula enquanto recurso e estratégia didática na formação de docentes para o
} ensino superior

\section{The lesson plan as resource and didactic strategy to prepare professors for higher education}

\section{Plan de clase como recurso y estrategia didáctica en la formación de docentes para la educación superior}

\section{Recebido: $13 / 12 / 2016$ \\ Aprovado: 26/03/2017 \\ Publicado: 31/10/2017}

Fabio Scorsolini-Comin 1

O objetivo deste ensaio é discutir sobre a utilização do plano de aula enquanto recurso e estratégia didática no processo de formação de docentes para o ensino superior. Descreve-se a experiência da disciplina de "Universidade e Docência", ofertada no Programa de Pósgraduação em Psicologia da Universidade Federal do Triângulo Mineiro. São apresentados modelos de organização de planos de ensino, de planos de aula e de avaliação da docência. Apresenta-se o plano de aula não apenas como um documento que orienta o planejamento dos conteúdos programáticos, mas como uma estratégia didática que se movimenta no acontecer da aula, representando uma possibilidade de diálogo constante entre conteúdos e sua execução prática em função de características dos docentes, dos alunos e da disciplina ministrada. Limitações e potencialidades dessa proposta são apresentadas e discutidas, bem como suas implicações para a formação de docentes para o ensino superior.

Descritores: Materiais de ensino; Ensino; Aprendizagem; Educação superior;

The purpose of this essay is to discuss the use of the lesson plan as a resource and teaching strategy in the process of training professors for higher education. It describes the experience of the subject "University and Teaching", offered at the Post-graduation Program in Psychology at the Federal University of Triângulo Mineiro, Uberaba/MG/Brazil. Organizational models of teaching plans, lesson plans and teaching evaluation are presented. The lesson plan is not presented merely as a document to guide the planning of programmatic content, but as a didactic strategy that changes as the classes happen, representing a constant possibility of dialogue between the content and its practical execution due to the characteristics of the professors, the students and the subject being taught. The limits and potential of this proposal are presented and discussed, as well as its implications for the training of undergraduate professors.

Descriptors: Teaching materials; Teaching; Learning; Education higher.

El objetivo de este ensayo es discutir sobre la utilización del plan de clase como recurso y estrategia didáctica en el proceso de formación de docentes para la enseñanza superior. Se describe la experiencia de la materia "Universidad y Docencia", ofrecida en el Programa de Pos-graduación en Psicología de la Universidad Federal do Triângulo Mineiro Uberaba/MG/Brasil. Son presentados modelos de organización de planes de enseñanza, de planes de clase y de evaluación de la docencia. Se presenta el plan de clase no solo como un documento que orienta el planeamiento de los contenidos programáticos, sino también como una estrategia didáctica que se mueve en el transcurrir de la clase, representando una posibilidad de diálogo constante entre contenidos y su ejecución práctica en función de características de los docentes, de los alumnos y de la materia transmitida. Limitaciones y potencialidades de esta propuesta son presentadas y discutidas, así como sus implicaciones para la formación de docentes para la enseñanza superior.

Descriptores: Materiales de enseñanza; Enseñanza; Aprendizaje; Educación superior.

1 Psicólogo. Especialista em Supervisão Escolar e Gestão Educacional. Mestre e Doutor em Psicologia. Pós Doutor em Tratamento e Prevenção Psicológica. Professor do Departamento de Psicologia e Coordenador do Programa de Pósgraduação em Psicologia da Universidade Federal do Triângulo Mineiro, Uberaba, MG, Brasil. ORCID: 0000-0001-6281-3371 E-mail: fabioscorsolini@gmail.com 


\section{INTRODUÇÃO}

$\mathbf{E}$ ste ensaio descreve a experiência da disciplina intitulada "Universidade e Docência", ofertada no Programa de Pós-graduação em Psicologia da Universidade Federal do Triângulo Mineiro (PPGP-UFTM), na cidade de Uberaba, Estado de Minas Gerais, como mote para a discussão acerca da formação de docentes para o ensino superior. Tal reflexão é orientada a partir de um recorte específico: a construção, o planejamento e a avaliação de planos de ensino e de planos de aula, conteúdos que permeiam a formação didática em programas de pós-graduação e também nas licenciaturas.

Em termos da organização do ensaio, inicia-se com uma breve apresentação acerca do cenário da pós-graduação em Psicologia, destacando alguns dos seus principais desafios e aberturas na contemporaneidade, especificamente no que tange à formação de docentes para o ensino superior. No tópico seguinte, apresenta-se o modo como foi construída a disciplina "Universidade e Docência", cerne da discussão acerca da formação docente.

$\mathrm{Na}$ sequência, destaca-se o plano de aula enquanto recurso e estratégia didática para a formação docente, sendo apresentadas algumas possibilidades de construção dos planos de aula e dos planos de ensino em disciplinas de cursos de graduação e de pósgraduação. Assim, o objetivo deste ensaio é discutir a utilização do plano de aula enquanto recurso e estratégia didática no processo de formação de docentes para o ensino superior.

\section{MÉTODO}

Este é um artigo de reflexão acerca da construção do plano de aula em uma disciplina de pós-graduação. Ele historiciza o curso de PPGP-UFTM, bem como apresenta aspectos conceituais de interesse à temática $\mathrm{e}$ à vivência prática da disciplina "Universidade e Docência". Após, são trazidas ilustrações práticas acerca do processo que envolve a construção, revisão e avaliação dessas ferramentas.

\section{RESULTADOS e DISCUSSÃO \\ Pós-graduação em Psicologia: desafios $e$ aberturas}

Especificamente em relação aos programas de Pós-graduação em Psicologia no Brasil, a área vem enfrentando um conjunto de desafios, entre eles a necessidade de maior abrangência geográfica e temática, o aperfeiçoamento do sistema de avaliação e a articulação dos diferentes resultados possíveis da pós-graduação em Psicologia, haja vista a heterogeneidade dos programas e da produção do conhecimento na área ${ }^{1}$. A internacionalização desses programas e sua necessidade de incrementos a uma formação metodológica mais sólida e ampla deve ser perseguida por seus responsáveis ${ }^{2}$.

Para além de um cenário promissor no que se refere à área da Psicologia, vem-se pontuando a necessidade de maior expansão ${ }^{3}$, notadamente em termos da existência de programas de pós-graduação em Psicologia em todos os Estados brasileiros, havendo recomendações para que as instituições que já possuem mestrado passem a contar com doutorado e que haja um crescimento anual de titulados na ordem de $10 \%$.

Em atenção a esses direcionadores, no ano de 2015 foram iniciadas as atividades do Programa de Pós-graduação em Psicologia da Universidade Federal do Triângulo Mineiro (PPGP-UFTM), localizado na cidade de Uberaba. A organização desse programa partiu das atividades do curso de graduação em Psicologia da UFTM, criado no ano de 2009, tendo sua primeira turma formada no primeiro semestre de 2013. A UFTM foi fundada em 1953, sendo federalizada em 1960 e transformada em Universidade em 29 de julho de 2005, pela Lei no 11.152. O PPGPUFTM emergiu como uma proposta para a formação de pesquisadores e docentes para o ensino superior derivada de uma das ênfases do curso de graduação: a "Produção do Conhecimento Científico em Psicologia”, com a oferta específica de conteúdos de formação em pesquisa.

0 objetivo geral do PPGP é "desenvolver estudos, pesquisas e docência 
na área de Psicologia, assim como formar profissionais capacitados para este fim". Como assinalado na proposta do PPGP, sua meta também é contribuir para a formação de docentes e pesquisadores em Psicologia alinhados com as novas perspectivas de produção do conhecimento científico, o que pode ser atestado, entre outros, pelas diretrizes do Programa Nacional de Pósgraduação (PNPG 2011-2020), publicado pela CAPES. Entre elas, recupera-se a necessidade de fomentar o desenvolvimento da Pós-graduação não como espaço de titulação, mas de real incremento na pesquisa científica, na internacionalização da produção brasileira, do estreitamento do diálogo com outras instituições de ensino, notadamente as estrangeiras, gerando inovação e a quebra do paradigma da reprodução e da imitação de pesquisas já realizadas $^{2}$. Deve-se investir cada vez mais na criação de uma base científica adequada e de ambientes apropriados para a experimentação e a criatividade ${ }^{4}$, o que envolve a formação de novos mestres e doutores visando à diminuição de assimetrias regionais relacionadas à formação qualificada e às oportunidades de trabalho.

Entre essas necessidades, a docência parece emergir como um aspecto por vezes negligenciado nos programas de pósgraduação ${ }^{5}$. Na intenção de formar pesquisadores de excelência, muitas vezes a docência é apresentada como uma função à parte e de menos valia, o que não corresponde aos direcionadores contemporâneos que compreendem que o pesquisar faz parte do rol de competência do ser docente. Assim, a formação do docente é algo mais amplo, sendo a atividade de pesquisa uma das possibilidades, talvez uma das mais importantes, dessa atuação ${ }^{6-10}$. A indissociabilidade entre docência e pesquisa atravessa muitas propostas de programas de pós-graduação, por vezes trazendo a formação em docência como algo essencialmente descolado de uma formação mais ampla e reflexiva, como uma dimensão auxiliar e complementar à pesquisa.
Os projetos de mestrado e doutorado e a densa formação em metodologias de pesquisa compõem um repertório típico que visa a formação do pesquisador. No entanto, a formação docente é compreendida, muitas vezes, como algo acessório e para o qual não é necessária uma formação específica, talvez por todos terem tido, ao longo da vida, contato com professores e com os processos de ensino e aprendizagem. Há, desse modo, uma naturalização da docência e do processo de formar-se como docente, o que fragiliza o processo de formação na pós-graduação, cujo foco é a atuação no ensino superior. Preconiza-se, desse modo, que a docência seja abordada na pós-graduação como uma formação inerente ao tornar-se pesquisador, promovendo uma leitura mais integradora na construção do egresso de um programa de mestrado, como o que será discutido mais particularmente neste ensaio. A partir dessa necessidade e buscando a formação de um profissional apto para atuação na docência, na pesquisa e na extensão universitária, o PPGP-UFTM criou a disciplina obrigatória intitulada: "Universidade e Docência" que será descrita a seguir. Busca-se, com isso, fomentar, desenvolver e problematizar a formação docente, instrumentalizando os mestrandos para a prática docente, tal como apresentado em outras propostas ${ }^{11,12}$.

\section{Universidade e Docência: proposta de uma disciplina para a formação docente}

Entre as disciplinas obrigatórias do Programa de Pós-graduação em Psicologia da UFTM encontra-se a de "Universidade e Docência", com carga horária de quatro créditos, correspondendo a 60 horas, que possui como ementa a discussão acerca da história da Universidade e da docência no ensino superior, bem como reflexões sobre desafios da Universidade, práticas docentes e formação na pós-graduação. Tal disciplina embasa, no programa, a realização do estágio em docência, que pode ocorrer a partir do segundo semestre do mestrado, com a participação do mestrando em atividades docentes junto à graduação, sob a supervisão de seu orientador ou do docente responsável pela disciplina. 0 estágio em docência é obrigatório no PPGP, em atenção ao processo 
de formação de professores para o ensino superior.

Dividida entre três docentes do programa, com vistas a diversificar as referências em termos dessa atuação, a disciplina divide-se em três módulos: $1^{\mathrm{o}}$ módulo: universidade; $2^{\circ}$ módulo: docência no ensino superior; $3^{\circ}$ módulo: estratégias de ensino e avaliação. Os dois primeiros módulos buscam situar o aluno diante da noção de Universidade, seu histórico, bem como o surgimento dos primeiros cursos de graduação e de pós-graduação no país ${ }^{9}$. Compreende-se que essa formação mais histórica é fundamental no sentido de permitir ao aluno uma leitura mais crítica acerca da atuação docente e do papel social ocupado pelos profissionais que atuam na educação, particularmente no ensino superior, como retratado na disciplina. Assim, são apresentados os panoramas históricos e perspectivas atuais acerca desses cursos, com foco na pós-graduação em Psicologia.

No segundo módulo são trabalhados aspectos inerentes à docência no ensino superior, como sua complexidade, desafios e potencialidades ${ }^{5,10}$. 0 último módulo, mais diretamente relacionado ao conteúdo do presente ensaio, destaca algumas das principais estratégias de ensino e de avaliação no ensino superior. Nesse sentido, são apresentadas aos alunos duas importantes ferramentas que atravessam o fazer docente: o plano de ensino e o plano de aula.

Como critério de avaliação da disciplina, os alunos são convidados a propor o desenvolvimento do plano de ensino para uma disciplina de graduação em Psicologia, que devem escolher, seja ela obrigatória ou eletiva, a partir da análise do projeto pedagógico do curso, disponibilizado no site da instituição. 0 plano de ensino deverá se basear na ementa da disciplina escolhida. A partir disso, o aluno deve desenvolver um plano de aula para uma disciplina de graduação em Psicologia, escolhendo uma aula que componha a disciplina selecionada para o plano de ensino. Esta aula, então, é apresentada à turma da pós-graduação, sendo avaliada conforme critérios disponíveis aos alunos e baseados nos mesmos aspectos verificados em concursos públicos da instituição de ensino. Esses critérios são apresentados no Quadro 1.

Quadro 1. Itens avaliados na aula do aluno da disciplina de Universidade e Docência (PPGPUFTM). Uberaba, 2017.

\begin{tabular}{|l|c|c|}
\hline \multicolumn{1}{|c|}{ Itens } & $\begin{array}{c}\text { Pontuação } \\
\text { máxima }\end{array}$ & $\begin{array}{c}\text { Pontuação } \\
\text { da aula }\end{array}$ \\
\hline $\begin{array}{l}\text { Avaliação do Plano de Aula de acordo com a aula a ser ministrada, observada a } \\
\text { coerência didático-metodológica, contendo os seguintes itens: tema da aula, } \\
\text { objetivos, conteúdos, metodologias, recursos, avaliação e referências. }\end{array}$ & 2,5 \\
\hline Domínio teórico-prático do seu campo de saber. & 2,5 & \\
\hline $\begin{array}{l}\text { Organização de ideias, clareza, coerência e comunicabilidade (espírito crítico, } \\
\text { fluência, objetividade e adequação da linguagem). }\end{array}$ & 3,0 & \\
\hline Adequação da exposição ao tempo previsto, com uso coerente do tempo. & 2,0 & \\
\hline Total & 10,0 & \\
\hline
\end{tabular}

Esses critérios, presentes nos editais de seleção docente, representam uma forma de balizar e uniformizar o modo como diferentes candidatos são avaliados. Ainda que esse processo possa ser questionado por apresentar uma visão mais limitada e parcial acerca de uma aula, que deveria ser apreendida e problematizada a partir da conjugação de diversos elementos que envolvem todo o seu planejamento, execução e avaliação, considera-se que tal recorte permite ao aluno de pós-graduação uma visão também alinhada ao que a maioria dos processos seletivos para a contratação de docentes vem requisitando na contemporaneidade. Assim, a disciplina busca levantar discussões mais amplas acerca do processo de avaliação de uma aula 
ou componente didático, por exemplo, mas também apresentando o modo como uma aula pode ser avaliada em uma perspectiva mais burocrática, pontual ou com um foco mais definido, que é a seleção de profissionais para atuarem como docentes. Para a disciplina do PPGP-UFTM houve uma alteração dos pesos dos itens, valorizando mais o primeiro quesito, que se refere ao plano de aula, em atenção aos objetivos da disciplina. Em concursos dessa instituição, o plano de aula possui peso um. Atesta-se, desse modo, o caráter essencialmente didático dessa atividade avaliativa na disciplina.

A qualidade de uma aula não pode se limitar a esses critérios, mas a sua disponibilização e clarificação aos candidatos podem orientá-los no sentido de se prepararem para esses processos seletivos. Tornar a avaliação um processo reflexivo e não-linear deve ser uma preocupação constante dos profissionais da educação. Segundo Hoffmann ${ }^{13}$, avaliar em meio aos novos paradigmas educacionais e culturais é dinamizar oportunidades de ação-reflexão, em um acompanhamento permanente do professor. 0 docente deve propiciar ao aluno, em seu processo de aprendizagem, reflexões acerca do mundo, formando pessoas críticas, participativas e articuladas às novas exigências da sociedade contemporânea ${ }^{14}$. Tais aspectos podem e devem nortear a construção de propostas didáticas corporificadas nos planos de aula.

Embora esses critérios sejam empregados pela instituição de referência e não sejam um modelo necessariamente usado em outras instituições, oferecem uma possibilidade de compreensão do que vem a ser uma aula do ensino superior. Esses critérios podem funcionar como um disparador para a construção de novos critérios, mais adequados a cada caso e a cada proposta.

Em termos da presente proposta, o primeiro critério orienta que o docente (ou o aluno em preparação para a docência, no caso da disciplina do PPGP-UFTM) deve apresentar um plano que esteja de acordo com a aula a ser ministrada, observada a coerência didático-metodológica. Frequentemente os alunos em formação optam por apresentar aulas que podem se assemelhar ao que se conhece como seminário, ou seja, o aluno apresenta o tema para uma plateia, cuidando para que o mesmo seja bem exposto e não haja erros ou equívocos em termos de conteúdo.

No entanto, uma aula requer cuidados especiais que se distanciam do seminário: não basta apresentar os conteúdos, é preciso criar condições para que as pessoas compreendam esses conceitos e sua importância para a sua formação. Assim, uma forma de ajudar o docente a construir esse percurso e contribuir para que o aluno o apreenda é solicitar a presença dos seguintes aspectos no plano de aula: explicitação do tema da aula, dos objetivos, dos conteúdos a serem trabalhados, das metodologias a serem empregadas para que se alcancem os objetivos, os recursos utilizados, bem como a avaliação da aula ministrada e a indicação das referências usadas em aula. Esses requisitos, se respeitados, já proporcionam uma visão de aula, distanciando-se do seminário com o qual os alunos egressos da graduação estão mais habituados.

Outro quesito avaliado refere-se ao domínio teórico-prático do campo do saber. Nesta categoria deve ser avaliado se o docente possui domínio da temática que está apresentando, se está alinhado aos principais conhecimentos naquela área, entre outros aspectos. Deve demonstrar que domina esses saberes e não apenas consegue explicá-los. Busca-se compreender se o docente possui repertório e eloquência na área. 0 docente não deve demonstrar apenas que estudou e se preparou para a aula, mas que também domina o seu campo de estudo e que consegue se articular na proposição de outras aulas e conteúdos relacionados a uma dada área. Já que nem sempre é possível assistir um candidato a docente apresentando diversas aulas, deve-se possibilitar acessar esse repertório a partir do que o candidato apresenta em uma dada aula.

0 terceiro quesito trata de aspectos como a organização de ideias, clareza, 
coerência e comunicabilidade (espírito crítico, fluência, objetividade e adequação da linguagem). É importante que a aula seja estruturada com uma sequência lógica, possuindo enquadre inicial, desenvolvimento e conclusão. Os conteúdos devem partir dos mais simples e gerais para os mais complexos e específicos. Aspectos como a objetividade e o espírito crítico devem estar presentes. É importante que se possa compreender se o aluno consegue planejar a aula do modo mais didático possível, ou seja, pensando na forma como um determinado conteúdo pode ser ensinado, explicitado ou apresentado da maneira mais adequada e coerente. Manterse coerente com o objetivo da aula é fundamental nesse processo, inclusive na escolha do que será apresentado, de que modo, bem como as formas de avaliar a compreensão e apropriação dos conteúdos por parte dos alunos.

A adequação da exposição ao tempo previsto, com uso coerente do tempo, é um aspecto técnico que, por vezes, acaba sendo central em uma aula, notadamente quando o docente (ou o candidato a algum concurso, por exemplo) não cumpre esse requisito. Normalmente, sugere-se uma aula de 50 minutos, com tolerância de cinco minutos para mais ou para menos, ou seja, a aula pode durar de 45 a 55 minutos. Quanto mais o docente treinar a sua apresentação e tiver segurança em relação ao que deve apresentar, maior a chance de ele se ater a esse tempo quando estiver sendo avaliado. Controlar o tempo é fundamental e isso pode ser feito com o apoio de um relógio, cronômetro ou mesmo da numeração dos slides quando estes forem utilizados, por exemplo, para que o docente se situe em termos do andamento de sua aula. Estar preparado para responder a imprevistos é também um treino importante nessa preparação.

\section{Plano de aula enquanto recurso $e$ estratégia didática}

O plano de aula, portanto, é um dos produtos entregues pelos alunos ao final da disciplina de "Universidade e Docência" durante suas apresentações finais, ou seja, suas aulas. 0 plano é empregado como forma de evidenciar que os alunos compreenderam não apenas como pode ocorrer à docência no ensino superior, mas também como esta ferramenta pode ser utilizada como forma de auxiliar a planejar a aula e os conteúdos da disciplina, bem como estruturar o programa, a fim de que os objetivos apregoados sejam atingidos. Neste ensaio, são trazidas duas concepções do plano de aula: (a) como recurso; (b) como estratégia didática.

Em sua maioria, os planos de aula são apresentados como recursos empregados, sobretudo, em processos seletivos e em concursos públicos nos quais se busca avaliar a didática de um candidato à docência no ensino superior. Na prática cotidiana, nem sempre os planos de aula são confeccionados ou claramente discutidos e apresentados aos alunos. Espera-se do candidato a capacidade de organização dos conteúdos e a proposição de estratégias de ensino e de avaliação condizentes com a temática que se pretende lecionar. Em muitos concursos e processos seletivos, a avaliação do plano de aula constitui um dos pré-requisitos da prova didática, de modo que candidatos que não apresentem o plano de aula ou não comentem aspectos cotejados pelo plano acabam sendo penalizados em termos de notas ou até mesmo desclassificados daquela etapa. Pressupõe-se, desse modo, que a capacidade de construção de um plano de aula é algo imprescindível para se avaliar a competência de um candidato ao cargo de professor.

No entanto, essa concepção de plano de aula explora esse material apenas como um recurso, como um objeto necessário para a apresentação da aula e que, por vezes, é confeccionado de modo automático, mecânico, sem a correta reflexão em torno do que é proposto, representando apenas um documento formal. Diversos modelos são veiculados, mas poucos são efetivamente discutidos. Mas em qual momento da pósgraduação o aluno em formação tem acesso a reflexões sobre a confecção do plano de aula? Notadamente, algumas dessas discussões são apresentadas em cursos de licenciatura, ou seja, durante a graduação. No caso específico da Psicologia, em que nem todas as 
instituições de ensino superior oferecem a modalidade licenciatura, essa formação pode ficar comprometida, sendo que o espaço da pós-graduação assume uma função muito importante nesse sentido, o de contribuir com a formação de docentes para a atuação no ensino superior ${ }^{2,5}$.

A partir dessa crítica, desenvolveu-se no presente ensaio a noção de que o plano de aula pode ser oferecido enquanto uma estratégia didática, algo que ultrapasse a noção de uma ferramenta auxiliar ou um documento que deva ser entregue pelo docente como parte de pré-requisitos meramente formais ou burocráticos inerentes à atividade docente. Isso equivale a dizer que o plano de aula não pode ser apenas um documento a ser entregue pelo docente no início da sua aula, mas que deve ser evocado como uma voz importante ao longo de toda a aula. Deve-se, portanto, dialogar com o plano de aula, não apenas utilizá-lo como um roteiro do que será apresentado ou abordado na aula. 0 plano também deve ser compreendido como uma estratégia em acontecimento, que pode ser constantemente reavaliada, reformulada, revista, criticada, ou seja, trata-se de uma dimensão em movimento. Abrir-se a esse movimento mostra-se tão importante quanto planejar e dimensionar corretamente a execução do que será apresentado.

É importante que o docente dialogue ao longo de toda a aula com os conteúdos disponíveis no plano de aula. 0 objetivo, por exemplo, não pode ser algo apresentado apenas no início da aula, mas deve ser retomado ao seu final, buscando compreender se o mesmo foi atingido ou não, e mesmo ao longo da aula, para que a sequência didática e os conteúdos apresentados possam ser justificados em função do objetivo. Ou seja, todo o programa selecionado para a aula e a sequência na qual o mesmo será apresentado ou abordado depende, fundamentalmente, do objetivo que se persegue. Esse objetivo pode ser recuperado sempre que necessário, tanto para se manter a proposta, o foco e a coerência da aula como também para fomentar o interesse dos alunos. Para aprender é importante, também, conhecer a utilidade, a intenção ou a necessidade de cada conteúdo ou de cada estratégia. Quando isso fica mais claro para o aluno, aumenta-se a chance de o processo educativo ocorrer a contento.

Na proposta da disciplina em apreço, os alunos são incentivados a fazer um uso mais didático do plano de aula, para além de uma exigência formal. Incentiva-se que os alunos utilizem o plano de aula o tempo todo, dialogando com o mesmo, fazendo possíveis ajustes em função do decorrer da aula, e das possíveis dúvidas lançadas e, até mesmo da reavaliação que ocorre com qualquer planejamento a partir do acontecer da aula. Pode-se, por exemplo, acompanhar a evolução do percurso narrado no plano, com o propósito de que os alunos, de fato, compreendam a sua importância.

Para alunos que estão em formação para se tornarem futuros docentes, é necessário evidenciar o modo como os conteúdos podem ser organizados, trabalhados, desenvolvidos e também repensados. Há sempre formas mais adequadas de lecionar em função da turma, dos conteúdos, do tempo que se tem disponível e de características do próprio docente. Entender o plano de aula enquanto um recurso dinâmico que, embora previamente planejado, pode ser alterado no acontecer da aula, é uma forma de não cristalizar a docência em uma categoria de manual, mas articulá-la às diversas nuanças da docência e do contato fundamental entre aluno e docente.

\section{Construção do plano de aula}

A chamada crise da educação científica ${ }^{15}$ revela que a perda de sentido do conhecimento científico para os jovens na contemporaneidade não só limita sua utilidade e aplicabilidade por parte dos alunos, mas também seu interesse ou relevância. Um dos motivos desse desinteresse reside no distanciamento cada vez maior entre a ciência que é ensinada nos meios educacionais e os próprios alunos, que não se sentem parte desse cenário, não se sentem parte dos conteúdos estudados, o que pode ser observado nos ensinos fundamental 
e médio, chegando até mesmo à modo esses conteúdos serão absorvidos e universidade.

recebidos pelos alunos. A possibilidade de

O plano de aula é uma ferramenta, um recurso e uma estratégia didática. Dada a sua relevância e complexidade, a sua construção mostra-se permeada por um difícil exercício que é o do planejamento. Esse planejamento envolve não apenas delinear o que ensinar e de que modo, mas tentar antever de que rever esse planejamento prévio pode ser entendida como uma característica de flexibilidade, retomando o sentido dinâmico do plano de aula. No Quadro 2 apresenta-se uma proposta de construção do plano de aula com os aspectos principais que podem ou devem estar presentes nesse documento.

Quadro 2. Modelo de plano de aula. Uberaba, 2017.

\begin{tabular}{|c|c|}
\hline \multicolumn{2}{|l|}{ Identificação } \\
\hline \multicolumn{2}{|c|}{ Nome da universidade (exemplo: Universidade de São Paulo) } \\
\hline \multicolumn{2}{|c|}{ Nome da faculdade (exemplo: Faculdade de Filosofia, Ciências e Letras de Ribeirão Preto) } \\
\hline \multicolumn{2}{|c|}{ Nome do departamento (exemplo: Departamento de Psicologia) } \\
\hline \multicolumn{2}{|c|}{ Nome da disciplina (exemplo: Aconselhamento Psicológico) } \\
\hline \multicolumn{2}{|c|}{ Período em que será ministrada (por exemplo: $2^{\circ}$ semestre de 2016) } \\
\hline \multicolumn{2}{|c|}{ Responsável (nome do docente) } \\
\hline \multicolumn{2}{|l|}{$\begin{array}{l}\text { Plano de Aula } \\
\text { Data: }\end{array}$} \\
\hline Tema & Plantão Psicológico: Constructos e Técnicas \\
\hline Objetivo & $\begin{array}{l}\text { Compreender a modalidade do plantão psicológico e conhecer alguns constructos e } \\
\text { técnicas que norteiam a atuação profissional na área. }\end{array}$ \\
\hline Conteúdos & $\begin{array}{l}\text { (1) Conceituais: Definição de plantão psicológico e das suas principais abordagens, } \\
\text { pesquisas e intervenções. } \\
\text { (2) Procedimentais: Como planejar, desenvolver e refletir sobre intervenções que } \\
\text { fazem uso da modalidade do plantão psicológico; Como desenvolver atitudes para a } \\
\text { escuta em plantão. } \\
\text { (3) Atitudinais: Quais as atitudes facilitadoras no contexto do plantão psicológico e o } \\
\text { que é esperado de um profissional que atue na área em termos de competências, } \\
\text { habilidades e atitudes. }\end{array}$ \\
\hline $\begin{array}{l}\text { Estratégias de } \\
\text { aula }\end{array}$ & $\begin{array}{l}\text { (1) Dinâmica de aquecimento ( } 10 \text { minutos) } \\
\text { (2) Aula expositiva ( } 50 \text { minutos) } \\
\text { (3) Avaliação da aula ( } 40 \text { minutos) }\end{array}$ \\
\hline $\begin{array}{l}\text { Dinâmica de } \\
\text { aquecimento }\end{array}$ & $\begin{array}{l}\text { (1) Reflexão individual sobre uma experiência pessoal de sofrimento e de necessidade } \\
\text { de busca de ajuda } \\
\text { (2) Se possível, escrever um pouco sobre a situação ou anotar os principais pontos }\end{array}$ \\
\hline Avaliação da aula & $\begin{array}{l}\text { (1) Discussão de um caso de atendimento em plantão psicológico realizado em uma } \\
\text { comunidade religiosa em pequenos grupos ( } 2 \text { a } 3 \text { pessoas) } \\
\text { (2) Discussão do mesmo caso com toda a sala }\end{array}$ \\
\hline Referências & $\begin{array}{l}\text { Leituras da aula: } \\
\text { Chaves, P. B., \& Henriques, W. M. (2008). Plantão psicológico: De frente com o } \\
\text { inesperado. Psicologia Argumento, 26(53), 151-157. } \\
\text { Mahfoud, M. (2013). Desafios sempre renovados: Plantão psicológico. In M. A. } \\
\text { Tassinari, A. P. S. Cordeiro, \& W. T. Durange (Orgs.), Revisitando o plantão } \\
\text { psicológico centrado na pessoa (pp. 33-50). Curitiba: CRV. } \\
\text { Para aprofundar: } \\
\text { Sehgal, R., Saules, K. Young, A., Grey, M. J., Gillem, A. R., \& Nabors, N. A. (2011). } \\
\quad \text { Practicing what we know: Multicultural counseling competence among clinical } \\
\text { Psychology trainees and experienced multicultural psychologists. Cultural Diversity } \\
\text { and Ethnic Minority Psychology, 17(1), 1-10. }\end{array}$ \\
\hline
\end{tabular}

Um primeiro aspecto a ser mencionado é a diferenciação entre tema e objetivo. $\mathrm{O}$ objetivo é o que se pretende com a aula acerca de determinado tema. No exemplo do Quadro 2, observa-se que o tema da aula está contido em seu objetivo, conforme destacado no itálico a seguir: o objetivo da aula é "compreender a modalidade do plantão psicológico (tema) e conhecer alguns constructos e técnicas (tema) que norteiam a atuação profissional na área". A redação do objetivo também deve estar 
escrita "para os alunos", ou seja, o objetivo deve ser alcançado pelos alunos ao final da aula ou do processo educativo. No exemplo em questão, ao final da aula sobre plantão psicológico, o aluno deve "compreender a modalidade do plantão psicológico e conhecer alguns constructos e técnicas que norteiam a atuação profissional na área". Os verbos empregados na redação do objetivo também denotam ações educativas, "compreender" e "conhecer". Não é o docente que deve compreender e conhecer, mas os alunos, ou seja, as pessoas que terão acesso à aula e aos conhecimentos ministrados ou mediados pelos docentes. A redação do objetivo deve estar sempre pautada por essa premissa: trata-se de um objetivo para o aluno.

Os conteúdos podem ser divididos em conceituais, procedimentais e atitudinais. Nem sempre os conteúdos podem ser organizados dessa forma, mas é importante que o aluno em formação tente sistematizar os conteúdos, de modo que consiga lidar com as diferentes exigências e necessidades que perpassam a construção de cada um desses conteúdos. Apresentar conceitos requer determinadas competências e envolve desafios específicos. Tratar de procedimentos requer habilidades com mais especificidades, incluindo, por exemplo, como planejar, como desenvolver, como refletir. Os procedimentos envolvem um "como fazer", um "como operacionalizar". Já os conteúdos atitudinais tratam basicamente de posturas que devem ser desenvolvidas e operacionalizadas. Referem-se a um "fazer" profissional, ao modo de encarar determinadas atividades, fenômenos e constructos na prática.

As estratégias de aula devem estar organizadas de acordo com o tempo que se tem disponível. É importante explorar diferentes estratégias, o que dependerá dos conteúdos a serem explorados e também do objetivo da aula. As estratégias de avaliação devem ocupar um lugar de destaque no plano, haja vista a necessidade de que as mesmas não ocorram apenas ao final do processo, como tradicionalmente ocorre, mas devem atravessar toda a aula13-14. As avaliações propostas podem ser mais tradicionais (verificação de assimilação de conteúdos, provas, testes) ou explorar atitudes de mediação, de diálogo, de construção conjunta de objetos de conhecimento, em uma perspectiva mais dialógica ${ }^{8}$.

O importante é que o aluno seja capaz de realizá-las a partir dos conteúdos explorados na aula, ou seja, as avaliações devem ser coerentes e compatíveis com o que foi ministrado, ensinado, conversado, produzido coletivamente. Opcionalmente, pode-se trabalhar com a possibilidade de que o aluno ultrapasse os conhecimentos apropriados durante a aula, devendo começar a desenvolver competências, por exemplo, que irão se solidificar ao longo das próximas aulas ou mesmo da disciplina. Assim, as avaliações podem apresentar um nível de exigência superior, tomando-se o cuidado de garantir apoio ao aluno nessa incursão em novos desafios e da complexidade da tarefa.

As avaliações também podem explorar aspectos individuais dos alunos ou de relacionamentos estabelecidos entre os mesmos em duplas, trios e mesmo com toda a turma. As leituras específicas da aula podem ser separadas em leituras prévias, em leituras realizadas ao longo da própria aula ou após a mesma, para fixação de conteúdos e reflexões. É importante que haja um claro roteiro de leitura, sendo que o docente pode também comentar tais referências, destacando pontos mais importantes nos quais os alunos devem se concentrar ou mesmo justificando a adoção dos mesmas dentro do objetivo didático proposto. As leituras devem ser articuladas e não meramente indicadas. A seguir, serão apresentadas considerações sobre a construção do plano de ensino.

\section{Construção do plano de ensino}

0 plano de ensino é um documento mais amplo que o plano de aula. Enquanto este é é construído individualmente para cada aula, aquele abarca todos os planos de aula de uma disciplina e refere-se, portanto, ao planejamento dos conteúdos didáticos de todo um conjunto de conhecimentos representado pela unidade disciplinar. 
A rigor, nem sempre um plano de ensino é solicitado na prova didática de um concurso. No entanto, no ensino da disciplina de "Universidade e Docência", alvo deste ensaio, o exercício de construção do plano de ensino é solicitado como forma de permitir que o aluno elabore as sequências didáticas e de conteúdo de toda uma disciplina. Essa organização pode ser útil na realização posterior do estágio em docência, obrigatório para a conclusão do mestrado neste programa. 0 Quadro 3 apresenta um modelo de plano de ensino para uma disciplina de Aconselhamento Psicológico.

Quadro 3. Modelo de Plano de Ensino. Uberaba, 2017.

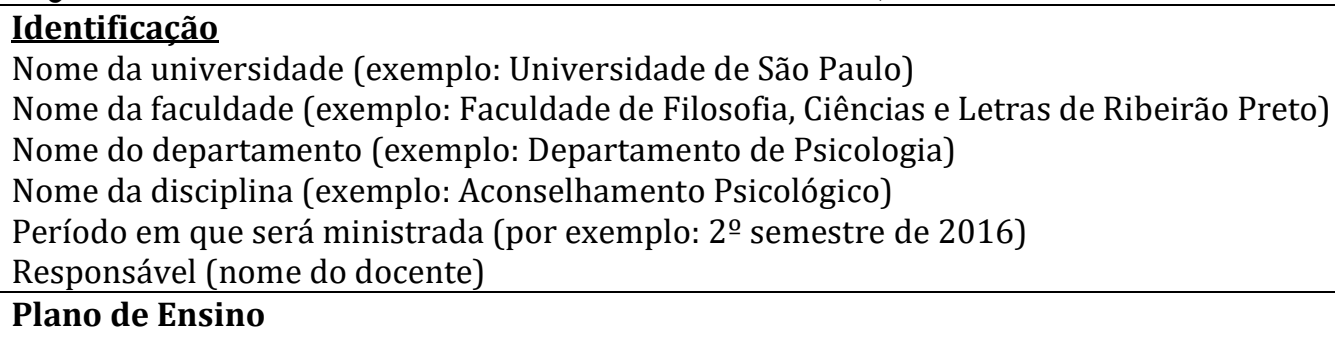

1. Histórico e conceituação do Aconselhamento Psicológico e do Plantão Psicológico.

2. Aconselhamento Psicológico em diversos contextos: entrevista, orientação educacional, orientação de carreira, psicoterapia, saúde, jurídico e educacional.

3. Aconselhamento Psicológico em diversas abordagens: psicodinâmica, comportamental, humanista, fenomenológico-existencial, Psicologia Positiva.

\section{Conteúdos procedimentais:}

1. Estabelecimento de uma relação de ajuda.

2. Procedimentos éticos na oferta de apoio psicológico.

3. Construção, implementação e avaliação de serviços de Aconselhamento e Plantão Psicológico.

4. Métodos de pesquisa em Aconselhamento Psicológico.

\section{Conteúdos atitudinais:}

1. Desenvolvimento de características pessoais do profissional para o estabelecimento de relações de ajuda.

2. Reflexões sobre a formação do terapeuta em termos de competências, habilidades e atitudes do profissional (autenticidade, empatia, maturidade emocional e consideração positiva sobre o ser humano e sobre si).

3. Estabelecimento de relação de ajuda como forma de vivência profissional.

Realização de estágio básico (60 horas):

1. Preparação teórica e técnica para a oferta do Aconselhamento Psicológico e do Plantão Psicológico em diferentes instituições.

2. Realização do estágio básico em diferentes instituições.

3. Avaliação do estágio básico em termos de conteúdos e atitudes desenvolvidas e a serem aprimoradas.

Método

Método

1. Aulas expositivas e conversas com profissionais que atuam na área

2. Leitura e discussão de textos em aula e em pequenos grupos

3. Vivências (exercícios em sala de aula)

4. Realização do estágio básico (não contemplado na carga horária de 45 horas da disciplina). 


\begin{tabular}{|l|l|}
\hline Avaliação & $\begin{array}{l}\text { Critério: A nota final será a média ponderada dos seguintes itens: } \\
\text { 1. Autoavaliação do aluno, apresentando seus critérios de avaliação e justificativa de } \\
\text { sua nota (peso 3) }\end{array}$ \\
2. Participação em aula, nas discussões e nos exercícios (peso 3) \\
3. Escrita de um ensaio teórico-vivencial sobre o estágio básico (peso 4) \\
Recuperação (média final inferior a 5,0): Prova escrita sobre todos os conteúdos da \\
disciplina.
\end{tabular}

Como se pode observar, os objetivos delineados são planejados para serem atingidos ao longo de toda a disciplina. Um mesmo objetivo específico, por exemplo, "conhecer as características de uma relação de ajuda" pode ser explorado em uma ou mais aulas. Cada objetivo específico pode ser explorado em um módulo próprio, por exemplo. 0 objetivo geral deve ser abarcado no conjunto de aulas da disciplina, ou seja, todos os objetivos específicos devem auxiliar a que se atinja o objetivo maior, a razão da disciplina, no caso, "propiciar ao aluno condições para reflexão sobre certos aspectos do relacionamento humano e, mais especificamente, de uma relação de ajuda". A redação dos objetivos segue a mesma orientação do que foi apresentado no plano de aula.

Do mesmo modo, as estratégias de ensino e as formas de avaliação devem atravessar toda a disciplina. Determinadas estratégias podem ser priorizadas em uma ou mais aulas. Aulas iniciais, por exemplo, podem trazer mais conteúdos conceituais, buscando instrumentalizar o aluno para acompanhar a sequência da disciplina. Aulas finais podem ser importantes para que sejam trabalhados mais conteúdos procedimentais e atitudinais, haja vista que os conceitos básicos já foram absorvidos e apropriados pelos alunos.

Construir planos de ensino e de aula envolve competências semelhantes, como a capacidade de reflexão e de planejamento de atividades e sequências didáticas. No entanto, o plano de ensino oferece a oportunidade de planejar toda uma disciplina, tendo como norteador a ementa da mesma. As ementas, normalmente, são estabelecidas nos projetos pedagógicos dos cursos de graduação e de pós-graduação e não podem ser alteradas a cada vez que a disciplina é oferecida, apenas quando há uma reformulação do projeto. Já os conteúdos e as estratégias podem ser alterados em função dos feedbacks oferecidos pelos alunos e pelas avaliações obtidas em cada oferta. Em termos das referências básicas e complementares, mesmo que o docente não utilize todas as obras indicadas em suas práticas pedagógicas, pode-se oferecer um norteador ao aluno, "em um documento que pode ser consultado durante todo o processo educacional e mesmo depois dele" 16 .

Observa-se, desse modo, que a exemplo do plano de aula, o plano de ensino também se mostra dinâmico. Ainda que as alterações e movimentações possam ocorrer ao longo da disciplina, é importante que haja 
um processo avaliativo da disciplina ao final da sua oferta, para que aspectos possam ser amadurecidos e melhorados para a próxima oportunidade. 0 docente deve estar atento para o fato de que cada oferta oferece um panorama específico de possibilidades e limitações, uma vez que variáveis se alteram (período do ano, turma, disponibilidade docente, demais atividades concorrentes, aspectos institucionais, entre outros).

0 que deve ser destacado é a potencialidade do ensino desses recursos (plano de aula e plano de ensino) também como estratégias de ensino que são passíveis de diálogo, movimentação e flexibilidade, em busca de maior adequação aos objetivos e às propostas didáticas. Os planos de ensino e de aula devem ser apropriados como recursos em movimento, assim como a própria atividade docente, o que pode contribuir para a formação de docentes mais reflexivos e abertos a mudanças, capazes de realizar o exercício do planejamento sem engessar as propostas e possibilitando revisões e reformulações em função do próprio correr do processo de ensino e aprendizagem.

Desenvolver o planejamento do ensino deve ser compreendido também como forma de conferir eficiência à ação humana ${ }^{17}$, orientando a tomada de decisões e mesmo possibilitando que revisões de percurso sejam feitas, acréscimos operados e conteúdos redimensionados em função de diversas condições. 0 planejamento ${ }^{18}$ das ações educacionais e dos processos de ensino e aprendizagem, embora não tenha sido o foco do presente ensaio, orienta diretamente as discussões em torno dos planos de ensino e de aula e deve ser um aspecto constantemente fomentado na pósgraduação, potencializando a formação de docentes para o ensino superior.

$\mathrm{Na}$ prática docente, esses planos podem ser elementos importantes no diálogo com os alunos, ultrapassando a noção de que seriam documentos comprobatórios e regulatórios dessa atuação. Ao ampliar os sentidos em torno desses recursos, agora compreendidos como estratégias didáticas, torna-se lícito o seu emprego como potencializador da atividade docente, o que pode e deve ser cada vez mais discutido nos programas de pós-graduação e nas disciplinas específicas de formação docente. A experiência aqui relatada, portanto, parece acenar para essa possibilidade na docência do ensino superior.

A reflexão acerca da docência também é algo importante. 0 professor reflexivo não pode ser um conceito autocontido e exclusivamente individual, mas justamente uma proposta de formação ao longo do tempo e de modo coletivo e dialogado ${ }^{7}$. Assumir a importância da formação docente nos programas de pós-graduação parece ser um desafio complexo ${ }^{2,5}$, mas que tem encontrado respostas que representam iniciativas excitantes para responder a essas demandas, como apresentado no presente estudo.

\section{CONCLUSÃO}

Este ensaio teve por objetivo discutir a utilização do plano de aula enquanto recurso e estratégia didática no processo de formação de docentes para o ensino superior. A partir da experiência de oferta da disciplina de "Universidade e Docência" no Programa de Pós-graduação em Psicologia da Universidade Federal do Triângulo Mineiro, pode-se considerar que o exercício de escrita e planejamento de aulas e disciplinas são aspectos centrais na formação de docentes do ensino superior.

Instrumentalizar os alunos para esse exercício mostra-se de suma importância, no intuito de demonstrar que a docência é uma atividade para a qual se prepara, não sendo a função docente algo que acompanha naturalmente o profissional que cursa um mestrado ou doutorado. É importante, portanto, fomentar a formação docente a partir dessas discussões e desses exercícios didáticos. Mesmo que os resultados dessa experiência ainda precisem ser avaliados a curto, médio e longo prazo, espera-se que a proposta possa disparar reflexões importantes nos docentes e coordenadores de programas de pós-graduação.

Conclui-se que tanto o plano de ensino quanto o plano de aula não podem ser percebidos e corporificados como 
documentos estanques e cristalizados, mas que, de fato, orientam o planejamento dos conteúdos programáticos e funcionam, concomitantemente, como uma estratégia didática que se movimenta no acontecer da aula e da disciplina, representando uma possibilidade de diálogo constante entre conteúdos e a sua execução prática em função de características dos docentes, dos alunos e da disciplina ministrada. Os docentes em formação precisam dialogar com esses recursos enquanto estratégias potentes para a execução dos processos de ensino e aprendizagem.

\section{REFERÊNCIAS}

1. Tourinho EZ, Bastos AVB. Desafios da pósgraduação em Psicologia no Brasil. Psicol Reflex Crit. 2010; 23(1):35-46.

2. Bastos AVB, Tomanari GY, Trindade ZA, Andery MAPA. The Psychology postgraduate system in Brazil: current characteristics and challenges for the area. Psicol Reflex Crit. 2015; 28(Suppl. 1):23-33.

3. Féres-Carneiro T, Bastos AVB, Feitosa MAG, Seidl-de-Moura ML, Yamamoto $\mathrm{OH}$. Gaps, goals and conditions for expanding graduate systems in psychology in Brazil. Psicol Reflex Crit. 2010; 23(1):11-24.

4. Barreto FCS, Domingues I. O PNPG 20112020: Os desafios do país e o Sistema Nacional de Pós-Graduação. Educ Rev. 2012; 28(3):17-53.

5. Bastos AVB, Yamamoto $\mathrm{OH}$, Menandro PRM. Formar docentes: em que medida a pós-graduação cumpre esta missão? (Réplica 1). Rev Adm Contemp. 2011; 15:1152-60.

6. Parente CMD, Valle LELR, Mattos MJVM, orgs. A formação de professores e seus desafios frente às mudanças sociais, políticas e tecnológicas. Porto Alegre: Penso; 2015. 256p.

7. Perrenoud P. A prática reflexiva no ofício de professor: profissionalização e razão pedagógica. Porto Alegre: Penso; 2002. 232p. 8. Scorsolini-Comin F. Diálogo e dialogismo em Mikhail Bakhtin e Paulo Freire: contribuições para a educação a distância. Educ Rev. 2014; 30(3):245-65.

9. Sguissard W. Reforma universitária no Brasil-1995-2005: precária trajetória e incerto futuro. Educ Soc. 2006; 27(96):102156.

10. Zabalza M. O ensino universitário. Porto Alegre: Artmed; 2005. 240p.

11. Conceição JS, Nunes CMF. Saberes docentes e professores iniciantes: dialogando sobre a formação de professores para o ensino superior. Rev Docência Ensino Sup. 2015; 5(1):9-36.

12. Dwek M, Motta ACGD, Thiollent MJ. Relato de experiência da disciplina "Seminários de Docência" do Programa de Engenharia de Produção da COPPE/UFRJ. Rev Docência Ensino Sup. 2015; 5(1):37-66.

13. Hoffmann J. 0 jogo do contrário em avaliação. Porto Alegre: Mediação; 2005. $176 \mathrm{p}$.

14. Scorsolini-Comin F. Avaliação dos processos de ensino-aprendizagem em ações educacionais ofertadas a distância. Temas Psicol. 2013; 21(3):335-46.

15. Pozo JI, Crespo MAG. A aprendizagem e o ensino de ciências: do conhecimento cotidiano ao conhecimento científico. 5ed. Trad. N. Freitas. Porto Alegre: Artmed; 2009. 296p.

16. Brambilla SDS, Stumpf IRC. Planos de ensino do curso de Biblioteconomia da Universidade Federal do Rio Grande do Sul: estudo bibliométrico de referências. Transinformação 2006; 8(1):37-47.

17. Gandin D, Gandin LA. Temas para um projeto político-pedagógico. Petrópolis: Vozes; 2003.176p.

18. Luckesi CC. Avaliação da aprendizagem escolar: estudos e preposições. 11ed. São Paulo: Cortez; 2001. 184p.

CONTRIBUIÇÕES
Fabio Scorsolini-Comin foi responsável por
todas as etapas do estudo, como
planejamento, escrita e revisão.


Como citar este artigo (Vancouver)

Scorsolini-Comin F. Plano de aula enquanto recurso e estratégia didática na formação de docentes para o ensino superior. REFACS [Internet]. 2017 [citado em inserir dia, mês e ano de acesso]; 5(3):415-428. Disponível em: link de acesso. DOI: inserir link do DOI.

\section{Como citar este artigo (ABNT)}

SCORSOLINI-COMIN, F. Plano de aula enquanto recurso e estratégia didática na formação de docentes para o ensino superior. REFACS, Uberaba, MG, v. 5, n. 3, p. 415-428, 2017. Disponível em: <link de acesso>. Acesso em: inserir dia, mês e ano de acesso. DOI: inserir link do DOI.

\section{Como citar este artigo (APA)}

Scorsolini-Comin, F. (2017). Plano de aula enquanto recurso e estratégia didática na formação de docentes para o ensino superior. REFACS, 5(3), 415-428. Recuperado em: inserir dia, mês e ano de acesso de Inserir link de acesso. DOI: inserir link do DOI. 